\title{
Non-Polymeric Nanogels as Versatile Nanocarriers: Intracellular Transport of the Photosensitizers Rose Bengal and Hypericin for Photodynamic Therapy
}

Ana Torres-Martínez, Begoña Bedrina, Eva Falomir, María J. Marín, César A. Angulo-Pachón, Francisco Galindo,* and Juan F. Miravet*

Cite This: ACS Appl. Bio Mater. 2021, 4, 3658-3669

Read Online

ACCESS | L W Metrics \& More | 回 Article Recommendations | (s) Supporting Information

ABSTRACT: The use of nanocarriers for intracellular transport of actives has been extensively studied in recent years and represents a central area of nanomedicine. The main novelty of this paper lies on the use of nanogels formed by a low-molecular-weight gelator (1). Here, non-polymeric, molecular nanogels are successfully used for intracellular transport of two photodynamic therapy (PDT) agents, Rose Bengal (RB) and hypericin (HYP). The two photosensitizers (PSs) exhibit different drawbacks for their use in clinical applications. HYP is poorly water-soluble, while the cellular uptake of RB is hindered due to its dianionic character at physiological $\mathrm{pH}$ values. Additionally, both PSs tend to aggregate precluding an effective PDT. Despite the different nature of these PSs, nanogels from gelator 1 provide, in both cases, an efficient intracellular transport into human colon adenocarcinoma cells (HT-29) and a notably improved PDT efficiency, as assessed by confocal laser scanning microscopy and flow cytometry. Furthermore, no significant dark toxicity of the nanogels is observed, supporting the biocompatibility of the delivery system. The developed nanogels are highly reproducible due to their non-polymeric nature, and their synthesis is easily scaled up. The results presented here thus confirm the potential of molecular nanogels as valuable nanocarriers, capable of entrapping both hydrophobic and hydrophilic actives, for PDT of cancer.

KEYWORDS: nanogels, organic molecular nanoparticles, nanovehicles, photodynamic therapy, drug delivery, nanomedicine, Rose Bengal, hypericin

\section{INTRODUCTION}

Nanomedicine, which uses biocompatible nanoparticles for diagnosis, delivery, or sensing purposes, ${ }^{1}$ has received extensive interest in recent years, as demonstrated by the increasing number of publications engaging with this topic. For example, more than 100 review papers were published in 2019 containing the term "nanomedicine" in the title. Nanomedicine constitutes a vast area of research due to the wide variety of nanoparticles that can be employed and the many therapeutic targets that can be introduced. A common approach in nanomedicine is to use nanocarriers for the intracellular delivery of molecular or macromolecular bioactive species. Examples include liposomes, solid-lipid nanoparticles, polymeric micelles and nanogels, polymer-drug conjugates, albumin, and silica nanoparticles. Despite the large number of potential nanomedicines reported in the literature, only a few tens of them have been approved by the Food and Drug Administration for clinical use due to the many pitfalls found in the translation from bench to clinical practice. ${ }^{2}$

Conventional polymeric nanogels (nanohydrogels), nanoparticles formed by polymeric networks that retain large quantities of water, have received extensive interest in recent years due to their potential for biomedical applications. ${ }^{3}$ Following the initial work from Vinogradov, the vast majority of nanogels consist of covalently cross-linked networks. ${ }^{4}$ Alternatively, examples of physically cross-linked nanogels have also been reported in the literature and include those formed by the self-assembly of amphiphilic block copolymers, ${ }^{5}$ hydrophobized polysaccharides, ${ }^{6}$ or DNA. ${ }^{7}$

Lately, our group has been interested in the study of molecular nanogels, namely, nanogels formed by aggregation of small molecules instead of polymers. ${ }^{8,9}$ The use of molecular nanogels aims to solve some critical drawbacks of polymeric nanogels in their use as biomedical carriers, ${ }^{10}$ such as biodegradability, stimuli responsiveness, polymer polydispersity, and batch-to-batch reproducibility. Interestingly, nanogels constituted by low-molecular-weight species have an apparent

Received: February 4, 2021

Accepted: March 18, 2021

Published: April 1, 2021 
relationship to their macroscopic counterparts, supramolecular (molecular) gels, which are soft materials formed by selfassembled fibrillar networks widely studied in recent decades. ${ }^{11}$

Nanocarriers are used for therapeutic applications with cancer being the central area of interest. ${ }^{12}$ In relation to this paper, photodynamic therapy (PDT) has been clinically used for the treatment of solid tumors for the past 25 years. ${ }^{13}$ PDT involves a systemically or topically administered photosensitizer (PS) followed by site-specific irradiation of the PS with the appropriate wavelength to generate reactive oxygen species (ROS). ${ }^{14}$ Site-specific irradiation causes cancerous cells to perish while sparing healthy tissues and organs, so PDT avoids the frequent systemic severe toxicity and adverse effects of other treatments. The mechanism to generate ROS consists of light absorption by the PS to yield the first excited state, ${ }^{1} \mathrm{PS} *$, and then, after intersystem crossing, the excited triplet state, ${ }^{3} \mathrm{PS}^{*}$. The latter is quenched by oxygen present in the medium $\left({ }^{3} \mathrm{O}_{2}\right)$ generating singlet oxygen $\left({ }^{1} \mathrm{O}_{2}\right)$ via the type II mechanism (energy transfer) and other cytotoxic species such as radical anion superoxide $\left(\mathrm{O}_{2}^{\bullet-}\right)$, hydroxyl radicals $\left({ }^{\bullet} \mathrm{OH}\right)$, or hydrogen peroxide $\left(\mathrm{H}_{2} \mathrm{O}_{2}\right)$ via the type $\mathrm{I}$ mechanism (electron transfer). ${ }^{15}$ The use of nanoparticles or nanocomposites for PDT has received increasing attention in recent years. ${ }^{16}$ In this paper, we specifically address the application of molecular nanogels for the delivery of PSs with the aim of improving the PDT efficiency of the actives.

Rose Bengal (RB, Scheme 1) is a water-soluble, well-studied synthetic dye that absorbs strongly around $550 \mathrm{~nm}$. It

\section{Scheme 1. Chemical Structure of Hydrogelator 1, RB, and} HYP<smiles>CCCCCCCCCNC(=O)[C@H](NC(=O)CCC(=O)O)C(C)C</smiles>
1<smiles>O=C([O-])c1c(Cl)c(Cl)c(Cl)c(Cl)c1-c1c2cc(I)c(=O)c(I)c-2oc2c(I)c([O-])c(Cl)c(I)c12</smiles>

Rose Bengal, dianionic form (RB)

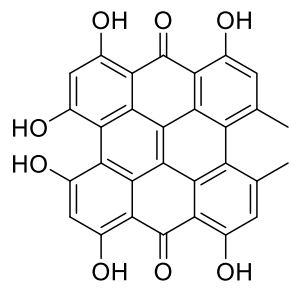

Hypericin (HYP) sensitizes the formation of ${ }^{1} \mathrm{O}_{2}$ with a high quantum yield $\left[\Phi\left({ }^{1} \mathrm{O}_{2}\right)=0.75\right.$ under $540 \mathrm{~nm}$ light irradiation], being a potent PS for type II PDT. ${ }^{17} \mathrm{RB}$ is versatile and applicable to a wide range of fields from photocatalysis ${ }^{18}$ to biomedicine. In this latter context, RB has had a profound impact as a therapeutic agent, with promising results in preclinical studies as a PS for PDT of cancer and the prevention of infectious diseases spreading. ${ }^{19}$ Besides, its long history of safe use in systemic diagnosis of hepatic functions as well as in ophthalmology has facilitated $\mathrm{RB}$ to advance into different clinical trials. An essential drawback in the therapeutic use of $\mathrm{RB}$ is that at physiological $\mathrm{pH}$, the predominant species is a dianion, which is inhibited from crossing cell membranes and suffers from poor intracellular uptake ability. ${ }^{20}$ The incorporation of the dye into nanocarriers has proved to overcome this limitation and, also, does not interfere in the photodynamic efficiency of $\mathrm{RB}^{21}$ For example, a favored intracellular accumulation and an enhanced phototoxic effect were achieved for RB loaded into silica nanoparticles (oral and breast cancer cells) ${ }^{22}$ and cationic dendrimers (basal carcinoma cells) ${ }^{23}$ and covalently bonded to gold nanoparticles (oral cancer cells). ${ }^{24}$ Higher phototoxicity was also reported for RB incorporated into silica nanoparticles (skin cancer cells), ${ }^{25}$ chitosan microcapsules (breast cancer), ${ }^{26}$ zinc oxide nanoparticles (cervical cancer cells), ${ }^{27}$ albumin (lung cancer cells), ${ }^{28}$ and polyamidoamine dendrimers (Dalton's lymphoma ascites cells). ${ }^{29}$

The other PS studied here, hypericin (HYP, Scheme 1), is a polyphenolic molecule obtained from the plant St. John's wort (Hypericum perforatum) with a broad pharmacological spectrum. It has an absorption maximum at $c a .590 \mathrm{~nm}$ and is also an efficient PS. ${ }^{30}$ Upon light activation, both type I and type II mechanisms have been proposed to explain its PDT activity. $^{31}$ Additional processes have been suggested as contributors of its phototoxicity as the formation of HYP radicals or a HYP-induced $\mathrm{pH}$ drop. ${ }^{32}$ Some advantages of the photosensitizing activity of HYP are its minimal or no dark toxicity $^{33}$ and its preferential accumulation in neoplastic tissues. $^{34}$ The HYP-PDT antineoplastic efficacy for cancer treatment has been demonstrated in several in vitro and in vivo studies $^{30}$ and three clinical trials for various skin disorders. ${ }^{35}$ The light-dependent fungicidal, bactericidal, and antiviral effects of HYP have also been reported. ${ }^{36}$ A critical drawback in the clinical application of HYP in PDT comes from its low water solubility. ${ }^{37}$ Furthermore, HYP tends to form nonfluorescent aggregates in aqueous media, which show a suppressed photodynamic activity and, therefore, low phototoxicity on cells. ${ }^{38}$ Several HYP nanocarriers have been investigated aiming to overcome these limitations. For example, encapsulated HYP in polylactic acid nanoparticles or copolymer micelles ${ }^{39}$ showed improved intracellular accumulation in ovarian tumor animal models; solid-lipid nanoparticles were useful as HYP transporters into cervical adenocarcinoma cells; ${ }^{40}$ and HYP encapsulated into block copolymers $^{41}$ and calcium phosphate nanoparticles ${ }^{42}$ improved the in vitro antimicrobial and antileishmanial PDT, respectively. Additional recent examples include HYP loaded in protein graphene oxide and composite nanoparticles. ${ }^{43}$

It has been stated that the use of nanocarriers is the defining characteristic of the so-called third generation of PSs. ${ }^{44}$ Ideally, these nanosystems should incorporate the PS without loss or alteration of the sensitizer activity. ${ }^{45}$ Here, we address the use of a novel nanocarrier, molecular nanogels, for the improvement of cellular uptake of RB and HYP and, thus, improvement of their PDT effect. As abovementioned, these molecules present opposite physicochemical nature, high polarity and water solubility for RB and low polarity and poor aqueous solubility for HYP, which, in both cases, leads to drawbacks for their use in clinical PDT. The results presented here highlight the versatility of the molecular nanogels used as carriers, which enhance cellular uptake of the sensitizers favoring their activity as PDT agents.

\section{RESULTS AND DISCUSSION}

The preparation of the molecular nanogels from gelator $\mathbf{1}[(S)$ 4-((3-methyl-1-(nonylamino)-1-oxobutan-2-yl)amino)-4-oxobutanoic acid, see Scheme 1] was previously reported in detail by our group. These particles have a gel-like nature as they are 
Scheme 2. Pictorial Representation of the Process Followed to Prepare PS@1 Nanogels

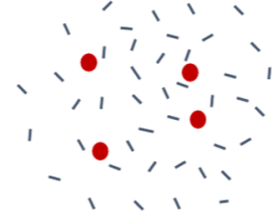

Hot solution of

$\mathbf{1}+\mathbf{P S}$ in toluene
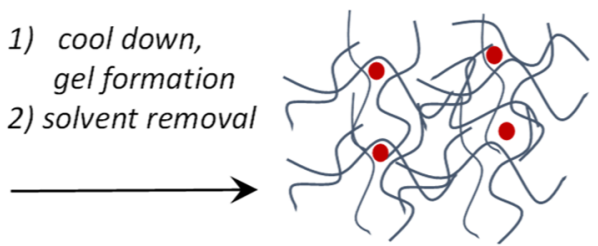

Xerogel

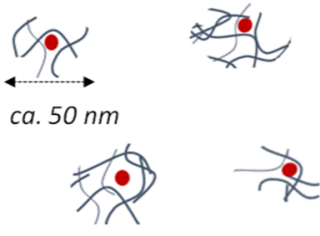

Nanogel particles

in aqueous medium

(PS@1)

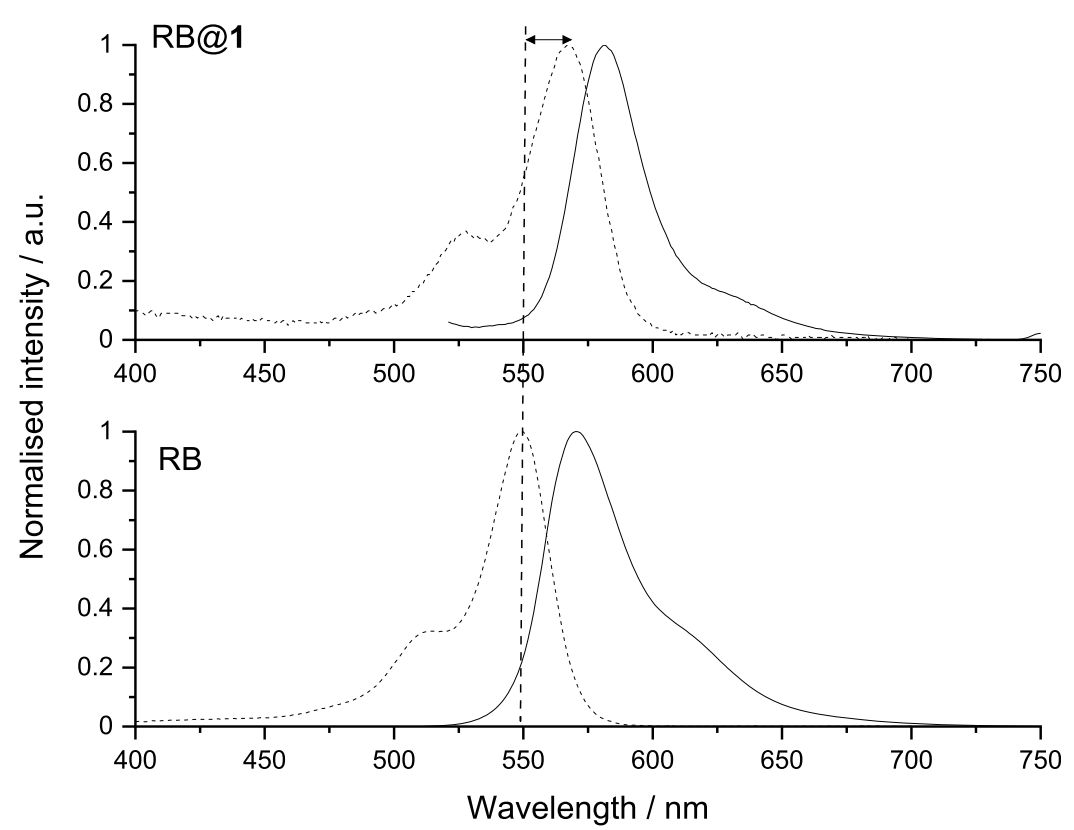

Figure 1. Normalized UV-vis absorbance (dashed line) and fluorescence emission (solid line, $\lambda_{\mathrm{ex}} 500 \mathrm{~nm}$ ) spectra for a representative RB@1 sample (top) and RB in PBS (bottom).

constituted mainly by water, according to static light scattering measurements. ${ }^{9}$ Scheme 2 outlines the preparation of PSloaded nanogels (PS@1) carried out in this work. In the first step, a gel of $\mathbf{1}$ in toluene is formed in the presence of the corresponding PS. Solvent removal under vacuum gave a xerogel film that was suspended, with sonication, in phosphatebuffered saline (PBS, pH 7) to afford a colloid containing PS@ 1 nanoparticles.

RB-Loaded Nanogels. Although RB is insoluble in toluene due to its ionic character, the gelator facilitated its dispersion in toluene. A related behavior has recently been reported by us for the same system in dichloromethane. ${ }^{46}$ Therefore, homogeneous gels in toluene containing RB could be prepared by cooling down to room temperature a hot solution containing $1(7.3 \mathrm{mM})$ and $\mathrm{RB}(40 \mu \mathrm{M})$. Following the procedure described above (xerogel formation and sonication), a colloid containing RB-loaded nanogels, RB@1, was obtained. The same protocol used to obtain RB@1 was repeated without $\mathbf{1}$, investigating how the different steps could affect RB. It was confirmed that the PS remained stable throughout the procedure.

The analysis of the RB@1 samples by ultraviolet-visible (UV-vis) spectroscopy (Figure 1) showed that the maximum absorption red-shifted from $549 \mathrm{~nm}$ for free RB to $\mathrm{ca}$. 560-570 $\mathrm{nm}$ for the RB@1 species in PBS. This red shift indicates RB being in a less polar environment in the nanogel than the one found in a conventional water solution. The strong solutesolvent interactions of $\mathrm{RB}$ with water, which stabilize the ground state of the PS, would be perturbed in the more hydrophobic environment of the nanogel. This type of effect diminishes the energy gap between the frontier orbitals, leading to $\lambda_{\max }$ red shifts in the absorption spectrum. Similar bathochromic shifts have been reported due to the incorporation of $\mathrm{RB}$ in hydrophobic environments. ${ }^{47}$ It has to be noted that the mentioned shift indicates that a significant amount of $\mathrm{RB}$ is loaded in the nanogel particles, but the presence of free RB in the system cannot be discarded. A 10 $\mathrm{nm}$ bathochromic shift was also observed for the maximum of the fluorescence emission spectra of the RB@1 samples (from ca. 570 to $c a .580 \mathrm{~nm}$ ).

$\mathrm{RB}$ tends to aggregate in dimers and higher multimers, a phenomenon that is detrimental for its use in PDT as ROS yields are reduced, and this aggregation can be estimated from the intensity ratio of the shoulder to the maximum peak in the absorption spectrum. The intensity ratio for RB@1 is almost identical to the ratio of a free RB standard solution in PBS, in which $\mathrm{RB}$ is in the monomeric form.

The amount of $\mathrm{RB}$ in these samples was determined by UV-vis spectroscopy. The absorption at the maximum intensity wavelength was used to calculate the concentration 

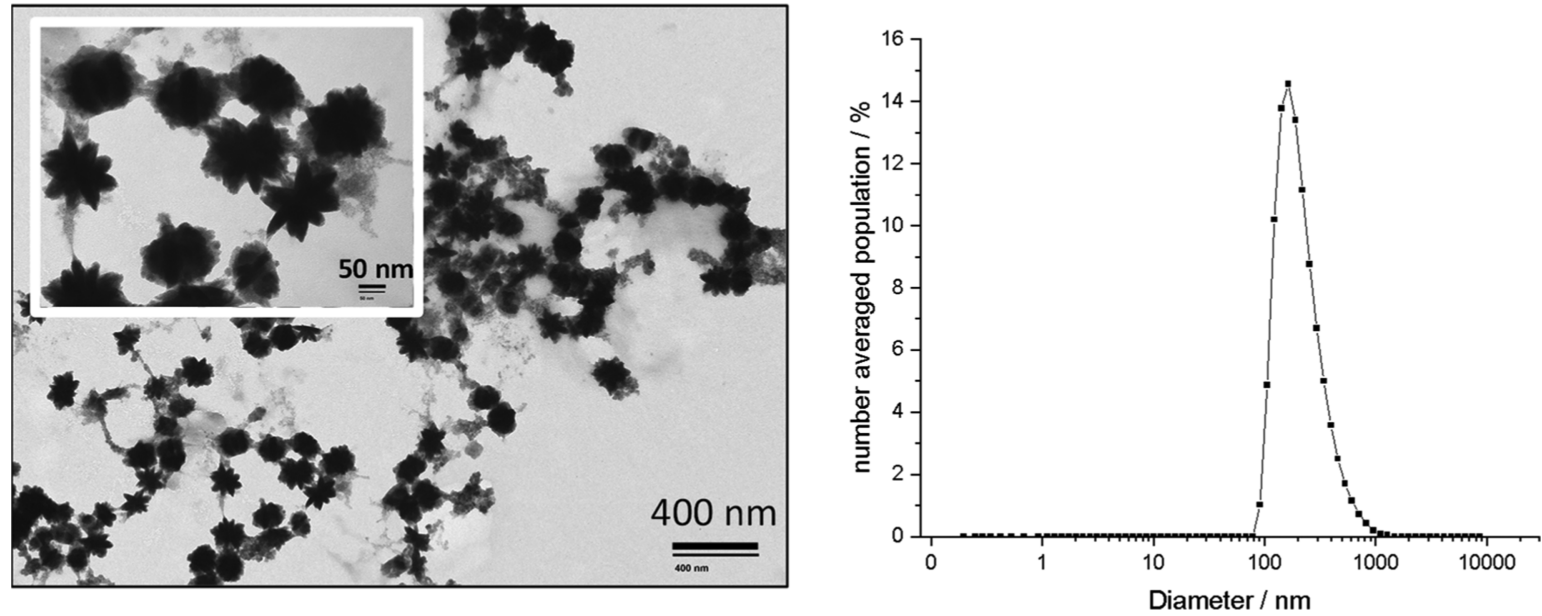

Figure 2. Analysis of RB@1 particles. TEM images (left) and number-averaged diameter distribution obtained by DLS (right).

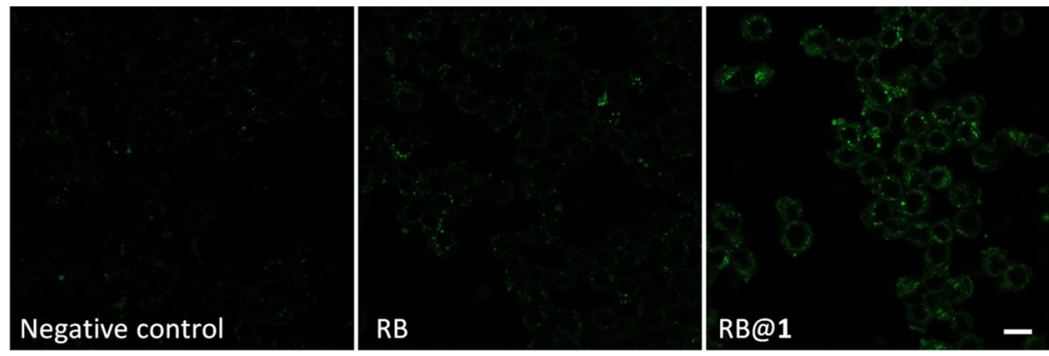

Figure 3. CLSM images of HT-29 cells incubated for $24 \mathrm{~h}$ with free RB and RB@1 nanogels $\left(\lambda_{\mathrm{ex}} 514 \mathrm{~nm}\right)$. The negative control corresponds to cells incubated with PBS. [RB] $=1.1 \mu \mathrm{M}$. Scale bar $=16 \mu \mathrm{m}$.

of RB based on a linear calibration constructed for free $\mathrm{RB}$ in PBS. It has to be noted that nanogel particles originate considerable light dispersion, resulting in a notable increase of the absorption baseline of the spectrum. For this reason, the quantification of RB was performed from baseline-corrected spectra (see Figures S1 and S2). The results obtained in this way were coincident with those achieved by nanogel disassembly by the addition of dimethyl sulfoxide (DMSO). The concentration of RB in RB@1 nanogel samples was found to present some variation in the different batches with an average value of $6 \pm 3 \mu \mathrm{M}$, which represents a drug loading of $0.8 \% \mathrm{w} / \mathrm{w}$ (the concentration of 1 in the samples was determined to be $0.7 \mathrm{mg} / \mathrm{mL}^{9}$ ). For control purposes, in the following experiments, $\mathrm{RB}$ solutions in PBS with the same concentration present in RB@1 samples were used.

RB@1 nanoparticles were characterized by dynamic light scattering (DLS) and transmission electron microscopy (TEM) (see Figure 2). DLS revealed a number-averaged diameter $\left(D_{\mathrm{n}}\right)$ of $218 \mathrm{~nm}$ (standard deviation $=6$, polydispersity index $=0.24$ ). Aging for $24 \mathrm{~h}$ or a $1: 3$ dilution in the cell culture medium did not modify the size distribution significantly. The $Z$-potential was determined to be $-33.9 \mathrm{mV}$ ( standard deviation $=4.1$, see Figure S15). This value indicates colloidal stability toward aggregation, and the negative value reflects the ionizable nature of the carboxylic acids, which should be in part as carboxylates in the nanogel.

Regarding TEM, spherical and spherulitic objects were observed, which, as proposed previously, ${ }^{9}$ would indicate that the nanogels would correspond to nucleation points that, in more concentrated solutions, would yield self-assembled fibrillar networks. The size of the particles observed by TEM is in good agreement with that obtained by DLS.

Samples were diluted $1: 3$ in the medium and tested in human colon adenocarcinoma cells (HT-29). This dilution was chosen because preliminary assays with 1 using the Trypan blue exclusion test revealed that a 1:3 dilution of the nanoparticles with the medium presented negligible cytotoxicity, slightly increased for a 1:2 dilution (see Figure S3). It has to be noted that the medium refers to Dulbecco's modified Eagle's medium (DMEM) used without the addition of phenol red to avoid interferences in optical measurements and, in the cases indicated in the Methods section, without fetal bovine serum (FBS) to promote starvation.

The incorporation of $\mathrm{RB}$ in the cells was studied using confocal laser scanning microscopy (CLSM) and flow cytometry after a $24 \mathrm{~h}$ incubation period with RB@1 nanogels. The solvent used to prepare the nanogels (PBS, $\mathrm{pH} 7$ ) was used as the negative control. As shown in Figure 3, the confocal microscopy analysis $\left(\lambda_{\mathrm{ex}} 514 \mathrm{~nm}\right)$ of cells incubated with RB@1 or free RB shows homogeneous fluorescence intensity revealing a non-specific distribution of the PS within the cytoplasm. Previous reports indicate that RB accumulates in membranes of normal cells, but it has been localized in lysosomes of melanoma cell lines. ${ }^{48,49}$ The apparent intensity of intracellular fluorescence measured by CLSM is notably higher for the cells treated with RB@1 nanogels than for those treated with $\mathrm{RB}$ alone. Flow cytometry analysis is entirely consistent with this observation. Three different nanogel batches were tested in duplicate, and the mean cell fluorescence intensity $\left(\lambda_{\mathrm{ex}} 488 \mathrm{~nm}\right)$ over the negative control for the RB@1 samples was found to be ca.70 times higher 
than that for the free RB solutions. Such a difference should not be ascribed to the interaction of $\mathrm{RB}$ with the nanocarrier, which increases only moderately RB fluorescence.

As previously mentioned, the low cellular uptake of free $R B$ is ascribed to its anionic character, resulting in reduced cellular membrane permeation. ${ }^{20,50}$ The PS entrapped in nanogels of $\mathbf{1}$ would act as stealth RB. Some authors have metaphorically coined this strategy "a Trojan horse approach". 51 Presumably, the enhanced cellular uptake is a consequence of differences in the mechanism of RB internalization. Endocytosis, a common mechanism described for internalization of nanosized particles, probably participates in the case of the nanometric gel particles. $^{52}$

The potential use of the RB@1 nanogels for PDT was also investigated. HT-29 cells were incubated for $24 \mathrm{~h}$ with either RB@1 nanogels or free RB in PBS and subjected to irradiation with a white light source [two light-emitting diodes (LEDs) with a $11 \mathrm{~W}$ power each, $\lambda_{\mathrm{em}}=400-700 \mathrm{~nm}$ ] for $2 \mathrm{~min}$. A negative control experiment was performed with HT-29 cells incubated with PBS and irradiated under the same conditions. The cell apoptosis and viability were studied $24 \mathrm{~h}$ after the irradiation. It has to be noted that once cells enter in contact with ROS, different mechanisms of cell death are triggered, with necrosis and apoptosis being the best known. Apoptosis is a gene-directed cell suicide process undergone when cells become damaged or are no longer needed. Necrosis has been considered a passive form of cell death occurring as a consequence of physical or chemical attack to the cell. Necrosis and apoptosis are very distinct morphologically since the former is accompanied with cellular and organelle swelling, membrane breakdown, and content release to the extracellular space, while apoptosis involves cell shrinkage and blebbing of the plasma membrane. ${ }^{53}$ A third mechanism, autophagy, is a predominantly cytoprotective process that has been linked to both necrosis and apoptosis death, serving either as a pro-survival or pro-death function. ${ }^{54}$ Finally, it must be recalled that the emerging paraptosis death mechanism gains increasing attention within the PDT community ${ }^{55}$ and could also play a role in explaining the activities of our systems. However, its study is out of the scope of this research. Elucidating which mechanism is operating in the cellular death provides useful information for the rationalization and improvement of PDT.

In the study of RB@1 PDT activity, viability and apoptosis were evaluated by flow cytometry using a commercial kit that double-stains the cell population. Apoptosis was inferred by staining with FITC-Annexin V, which detects externalized phosphatidylserine, a feature of the early phases of apoptosis. Viability was detected with propidium iodide (PI), which signals the loss of membrane integrity that accompanies the later stages of cell death. Three different batches of RB@1 nanogels were tested in duplicate, and the results are summarized in Figure 4 (see the dot plot in Figure S13). RB@1 internalization results in a dramatic enhancement of the measured PDT activity when compared to the cells treated with free RB and with PBS. These findings are in accordance with the higher efficiency of cellular uptake of RB@1 than that of free RB. RB@1 produces an apoptotic induction of more than $70 \%$ of the cell population. In comparison, the percentage of apoptotic cells for HT-29 cells incubated with free RB was close to the basal level of $15 \%$ observed for the PBS control. Only apoptosis was observed as a cell death mechanism in both staining and scattering analysis of flow cytometry data.

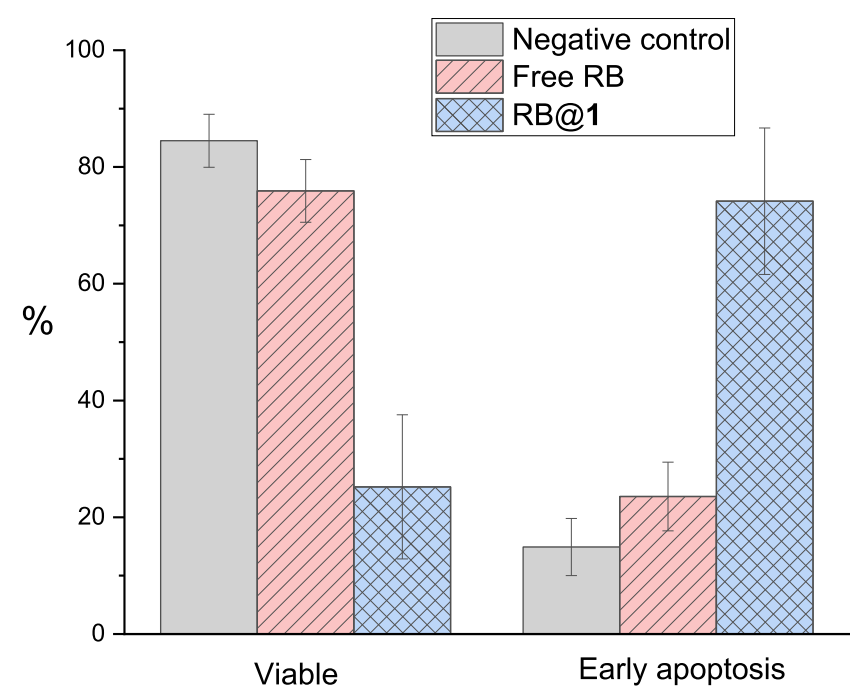

Figure 4. Results obtained by flow cytometry of cell viability and early apoptosis in PDT experiments (2 min irradiation) with HT-29 cells and RB as a PS. Annexin V-FITC/PI was used for staining. The negative control corresponds to cells incubated with PBS. The results are the average of three different batches analyzed in duplicate (the average $[\mathrm{RB}]$ in culture media was $2 \mu \mathrm{M}$ ).

This result is in agreement with a previous report that also finds apoptosis to be the preferred mechanism of cell death using RB. ${ }^{56}$ Regarding dark toxicity, no significant increase in cell death was observed when the cells were incubated under the same conditions as those indicated in Figure 4 but were not subject to irradiation (Figure S4), thus confirming the biocompatibility of RB@1. The phototoxicity of unloaded nanogels was also investigated using flow cytometry, and no cell death was observed when HT-29 cells were incubated with nanogels without RB and irradiated for 2 min (Figure S5).

Comparison with precedent in vitro studies using other nanocarriers has only a relative value considering the different types of cells examined and experimental conditions. The use of RB-loaded cationic dendrimers resulted in an induction of apoptosis to $40-60 \%$ of different basal carcinoma cells. ${ }^{23}$ In another example, organically modified mesoporous silica nanoparticles loaded with RB reduced $c a .40 \%$ cell proliferation in a skin cell cancer culture compared to the control. ${ }^{25}$

As $\mathrm{RB}$ is a type II PS, the photogeneration of ${ }^{1} \mathrm{O}_{2}$ in aqueous solutions of RB@1 was spectroscopically measured using 9,10anthracenediyl-bis(methylene)dimalonic acid (ABDA) as an ${ }^{1} \mathrm{O}_{2}$ chemical trap, which is a water-soluble probe for this ROS. ${ }^{57}$ It was observed that the entrapment of $\mathrm{RB}$ in the nanogel reduces moderately the rate of ${ }^{1} \mathrm{O}_{2}$ production, with the kinetic constants being measured 8.8 and $22.5 \mathrm{mM}^{-1}$. $\min ^{-1}$ for RB@1 and RB, respectively (Figure S6). A possible rationale for this behavior is that the nanogel environment lowers the diffusion rate of $\mathrm{O}_{2}$ inside the nanogel and consequently the diffusion of ${ }^{1} \mathrm{O}_{2}$ outside of the nanoparticle. ${ }^{58}$ Also, it has to be noted that the efficiency of ${ }^{1} \mathrm{O}_{2}$ generation in a cuvette and hence in the absence of cells could not be reflecting the situation in the biological context since once the RB@1 system crosses the cellular membrane, the PS could be released due to the disassembly of the nanoparticle.

HYP-Loaded Nanogels. HYP-loaded nanogels (HYP@1) were obtained from a gel of $\mathbf{1}$ in toluene formed in the presence of HYP $(25 \mu \mathrm{M})$, which is soluble in hot toluene in the $\mu \mathrm{M}$ range of concentrations used in this experiment. As 

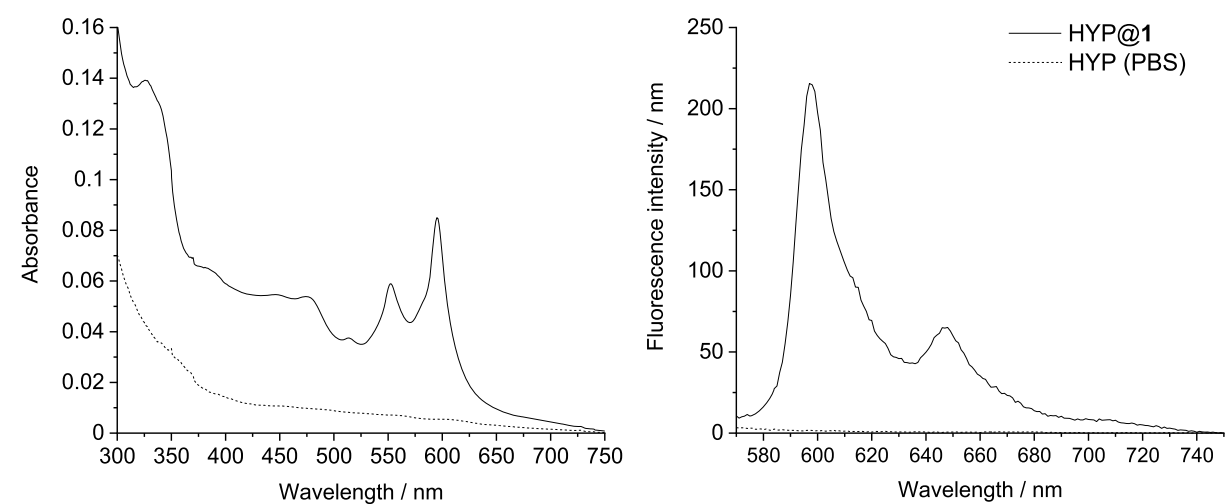

Figure 5. UV-vis absorption and fluorescence emission $\left(\lambda_{\mathrm{ex}} 550 \mathrm{~nm}\right)$ spectra of a representative HYP@1 sample (solid line) and HYP in PBS (dashed line).
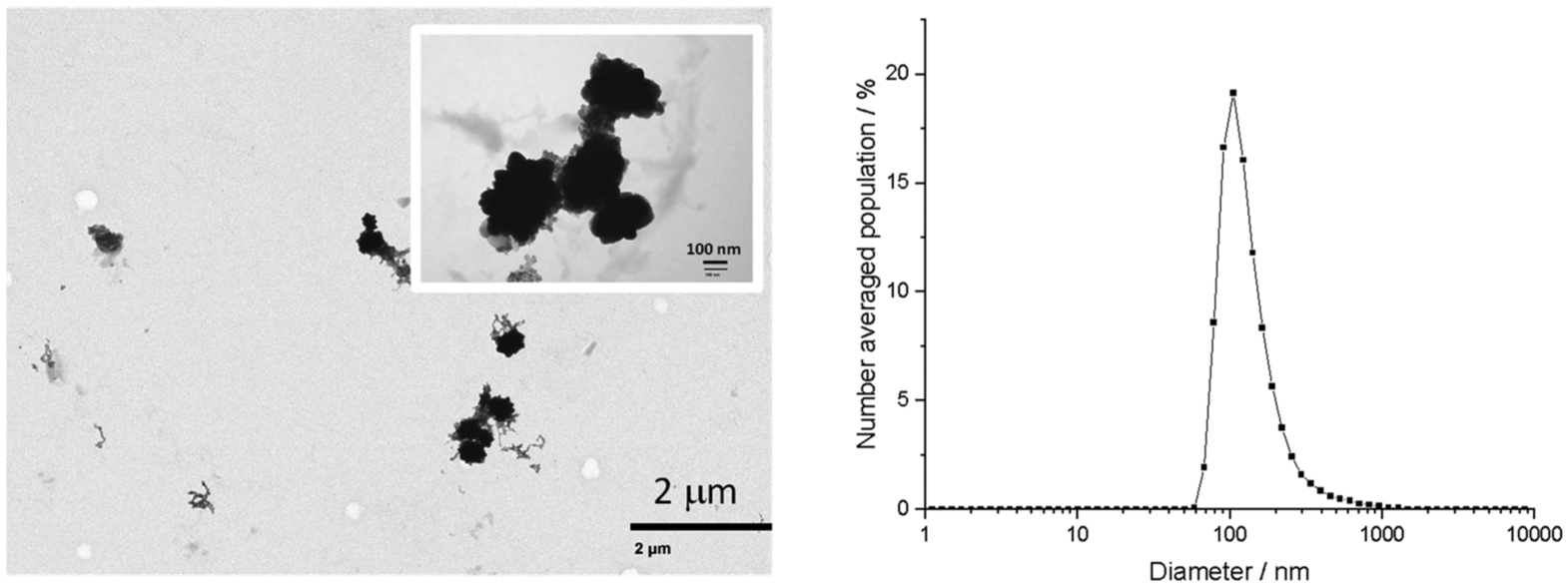

Figure 6. Analysis of HYP@1 particles. TEM images (left) and number-averaged diameter distribution obtained by DLS (right).

described in Scheme 2, solvent removal affords a xerogel, which is sonicated in PBS to form a sample of HYP@1 nanogels. As shown in Figure 5, the absorption spectrum of HYP@1 exhibits two well-defined peaks in the range of 525$625 \mathrm{~nm}$, with the dominance of the red-most band. However, the absorption spectrum of HYP in PBS shows a broadening of visible bands and a less vibronic structure (Figure S7). These data suggest that the monomeric form of HYP is present in the nanogels. In contrast, aggregates are formed in the absence of nanoparticles. Similar absorption spectra, ascribable to the monomeric form of HYP, have been previously reported for the incorporation of this molecule in membranes, nanoparticles, or proteins. ${ }^{59}$ As for fluorescence, HYP@1 in PBS shows a fluorescence emission spectrum with band maxima at 597 and $647 \mathrm{~nm}$, while HYP in PBS shows no fluorescence under the same conditions. These results also point to the presence of free HYP in the nanogels and aggregated, nonemissive HYP in the aqueous medium.

A blue shift going from HYP in DMSO to HYP@1 in PBS is detected for both absorption and emission maxima (Figure S7; 599-596 and 603-597 nm, respectively). This maxima displacement indicates that the environment of HYP in the nanogels presents reduced polarity compared to DMSO. ${ }^{60}$ HYP could be establishing $\pi-\pi$ interactions with hydrophobic areas or hydrogen bonds with the gelator molecules, as has been suggested for other systems. ${ }^{61}$

The quantification of HYP in the nanogel samples was performed by UV-vis spectroscopy. The absorption at the maximum intensity wavelength was used to calculate the concentration of HYP based on a linear calibration made from free HYP in DMSO. As in the case of RB@1, HYP@1 nanogel particles originate considerable light dispersion, and quantification of HYP was performed from baseline-corrected spectra (see Figure S2). The results obtained in this way were coincident with those achieved by nanogel disassembly by the addition of DMSO. An average loading of $0.7 \pm 0.3 \mu \mathrm{M}$ of HYP $(0.05 \%$ w/w drug loading) was obtained. Similar loadings were reported for other HYP-encapsulated systems. ${ }^{41,62}$ Samples prepared as HYP@1 nanogels but without the addition of the gelator were used as a control (HYP in PBS from here on). The maximum concentration of HYP that can be solubilized in PBS by this method was $0.09 \pm 0.05 \mu \mathrm{M}$, which is 1 order of magnitude lower than the solubility in the presence of the nanogels.

HYP@1 nanoparticles were characterized by DLS and TEM (see Figure 6). The results are similar to those obtained for RB@1 samples regarding both the morphology and sample stability. DLS revealed a $D_{\mathrm{n}}$ value of $137 \mathrm{~nm}$ (standard deviation $=7$, polydispersity index $=0.32$ ). Aging for $24 \mathrm{~h}$ or a $1: 3$ dilution in the cell culture medium did not modify the size distribution significantly. Additionally, the $Z$-potential was similar to that measured for RB@1, with a value of $-36.1 \mathrm{mV}$ (standard deviation $=1.8$, see Figure S16).

The cellular uptake of HYP@1 by HT-29 cells was also studied using flow cytometry and CLSM similarly as described above for RB@1. HT-29 cells were incubated for 24 h with 

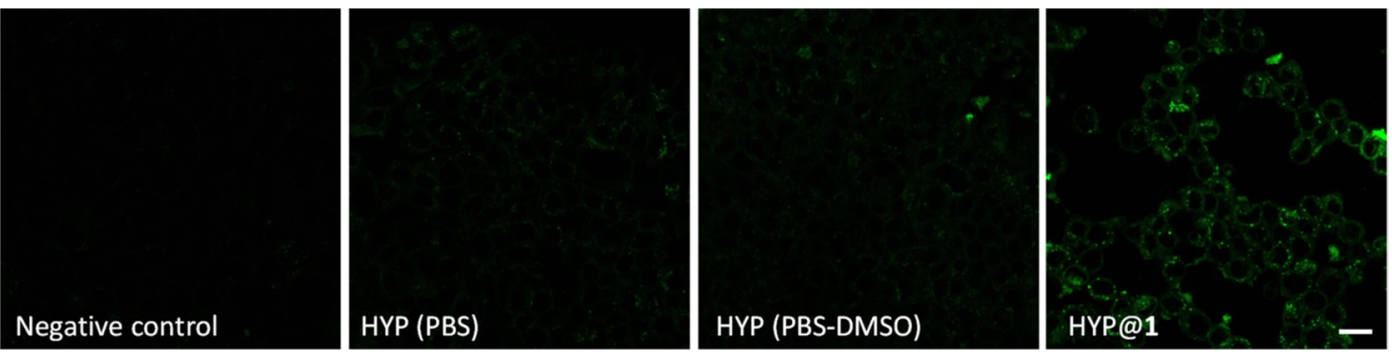

Figure 7. Images from CLSM; $\lambda_{\mathrm{ex}} 561 \mathrm{~nm}$. Cells were incubated for $24 \mathrm{~h}$ with the samples. [HYP] $=0.2 \mu \mathrm{M}$. Scale bar $=20 \mu \mathrm{m}$.

HYP@1 nanogels, and the average fluorescence emission per cell measured by flow cytometry was used as an indicator of the internalization of HYP. Due to the very low solubility of HYP in PBS, control samples at the same concentration were prepared using $1 \% \mathrm{v} / \mathrm{v}$ DMSO as a co-solvent (from here on, PBS-DMSO). However, PBS without any DMSO was used as the solvent for the samples with HYP@1. Flow cytometry analysis of three different nanogel batches was performed in duplicate. The mean cell fluorescence intensity $\left(\lambda_{\text {ex }} 488 \mathrm{~nm}\right)$ was found to be ca. 3 times higher for the HYP@1 system than for the sample containing HYP in PBS-DMSO. Moreover, the internalization of HYP for cells incubated with HYP@1 in PBS gave a 14 times higher fluorescence intensity than that obtained for HYP dispersed in PBS without DMSO. Care should be taken to interpret the intracellular fluorescence intensity of HYP due to the sensitivity of its emission efficiency to aggregation and polarity. It is assumed that the nanogel is disassembled in the cell, and the HYP emission from the different samples can be compared. CLSM images (Figures 7 and S8) agree qualitatively with the flow cytometry data, indicating significantly higher emission inside the cells treated with HYP@1 than inside cells treated with free HYP administered in PBS or in PBS-DMSO. The images reveal that HYP is preferentially accumulated in the membrane when cells are incubated with the HYP in PBS-DMSO sample (see Figure S5). However, when HYP@1 is studied, HYP is localized in the cytoplasm in a non-specific manner. It has been reported that HYP, due to its pronounced hydrophobic character, accumulates in lipid membranes. ${ }^{63}$ Noticeably, it was described that for HeLa cells, the use of serum in the culture media with HYP led from a plasma membrane staining (with non-fluorescent aggregates in the rest of the cell) to a nonspecific, cytoplasmic localization. ${ }^{64}$ This could be the case for HYP@1 nanoparticles, and the nanogel would play a similar role to that of the serum proteins.

The efficiency of HYP@1 for in vitro PDT was also studied in HT-29 cells, as described above for RB@1. For HYP@1, viability and apoptosis were detected based on changes in the permeability of cell membranes using a commercial kit with YO-PRO-1/PI staining. Three different batches of HYP@1 nanogels were tested in duplicate, and the results are summarized in Figure 8 (see the dot plots in Figure S14). Irradiation of cells incubated with HYP@1 in PBS and HYP in PBS-DMSO caused in both cases a significant reduction in cell viability. For example, the cell viability is ca. $10 \%$ for HYP@1 and 85\% for negative controls. On the other hand, no photoactivity was found for controls using HYP in PBS without DMSO, with the percentages of viable cells being near the basal level (see Figure S9). Also, low dark toxicity was observed in all cases (see Figure S10).

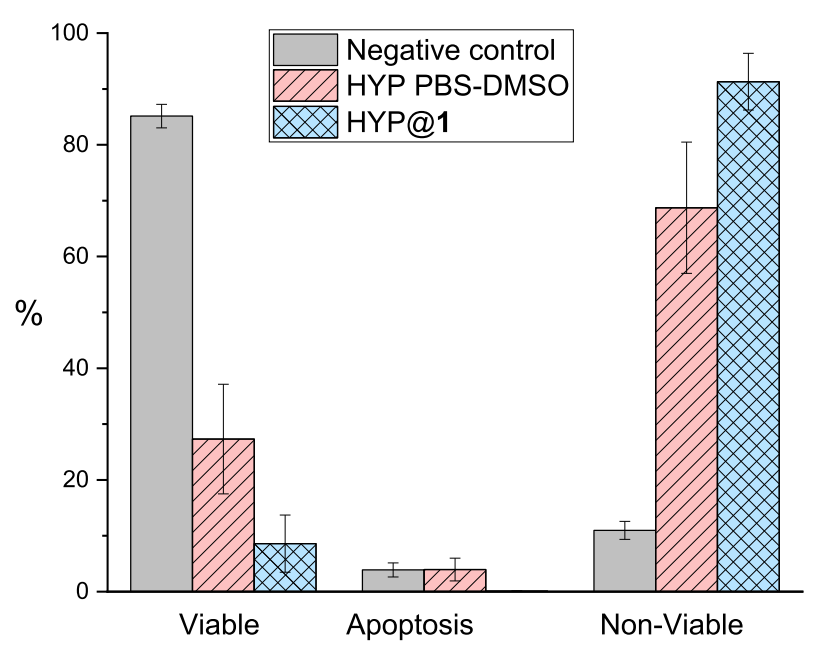

Figure 8. Results obtained by flow cytometry of cell viability and apoptosis in PDT experiments (2 min irradiation) with HT-29 cells and HYP as a PS. YO-PRO-1/PI was used for staining. The negative control corresponds to cells incubated with PBS. The results are the average of three different batches analyzed in duplicate. $[\mathrm{HYP}]=0.2$ $\mu \mathrm{M}$.

Irradiation of the cells in the presence of HYP@1 shows, according to the alterations in the light scattering pattern of the cells observed by flow cytometry (Figure S14), a prevalence of necrosis over apoptosis. This effect had also been observed previously in HT-29 cells treated with HYP and exposed to an extensive range of PDT doses. ${ }^{65}$ Protocols favoring apoptosis are recommended when PDT is applied for curative treatment of in situ neoplasia. However, the induction of necrosis, accompanied with an inflammatory reaction, has been reported as a good option for curing infiltrative tumors. ${ }^{66}$ The PDT activity obtained here is comparable to that described for HYP entrapped in glyconanoparticles, which afforded cell viability in the range of $20-50 \%{ }^{43}$

A relevant advantage of HYP@1 over free HYP for their use in PDT is the avoidance of DMSO as a co-solvent. The use of solvents in cell cultures, commonly ethanol and DMSO, has some drawbacks that should not be neglected. For example, water-DMSO systems with 0.25 and $0.5 \%$ of the organic solvent induce inhibitory effects in some cell types and a stimulatory impact in others. ${ }^{67}$ Besides, the proportion of a cosolvent can change in biological media, causing HYP aggregation.

Finally, the study of photogeneration of ${ }^{1} \mathrm{O}_{2}$ in aqueous solutions of HYP@1 by ABDA revealed that the photoactivity is similar to that of aggregated, poorly fluorescent HYP in PBS control samples (kinetic constants of $1.9 \times 10^{-4}$ and $1.1 \times$ $10^{-4} \mathrm{~s}^{-1}$, respectively, see Figure S6). These results are in sharp contrast with the much more effective PDT observed in cells 
treated with HYP@1 compared to those treated with HYP in PBS. A rationale for this behavior could be that encapsulation of HYP in the nanogel blocks significantly its action as a PDT agent, with the system being activated for PDT upon intracellular nanogel disassembly. A similar effect was observed for the encapsulation of HYP in solid-lipid and polylactic acidbased nanoparticles. ${ }^{40}$ Alternatively, it must be recalled that other ROS different from ${ }^{1} \mathrm{O}_{2}$ have been reported for HYP. ${ }^{31}$ Hence, a more in-depth study would be needed to disclose which mechanism (type I or II), namely, which ROS $\left({ }^{1} \mathrm{O}_{2}\right.$ or $\mathrm{O}_{2}{ }^{\bullet-}$ ), is responsible for the observed PDT effects. The cytotoxic ability of ${ }^{1} \mathrm{O}_{2}$ has been linked to apoptotic changes, while the impact of $\mathrm{O}_{2}{ }^{--}$is more associated with lipid oxidation, altering membrane functions. ${ }^{68}$ The different cell death mechanism observed for each ROS would reinforce the idea that the necrotic effects of HYP reported here are more likely due to $\mathrm{O}_{2}{ }^{\bullet-}$ at membranes than due to ${ }^{1} \mathrm{O}_{2}$.

\section{CONCLUSIONS}

The use of non-polymeric, molecular nanogels as vehicles for intracellular transport of actives has been hardly studied to date. Here, the nanogels formed by compound 1, whose preparation and characterization were reported in a previous work, ${ }^{9}$ show the capability of entrapping and promoting intracellular transport of two PDT agents, RB and HYP. These PSs present markedly different physicochemical characteristics. $\mathrm{RB}$ is a dianionic species at neutral $\mathrm{pH}$ and water-soluble, while HYP is rather hydrophobic. These two compounds can be considered paradigmatic examples of substances that need vehicles for intracellular transport. The cellular membrane hinders the intracellular transport of anionic species like RB. At the same time, hydrophobic compounds such as HYP present such low solubility in plain water that their concentration in solution is not enough to be effective in PDT. Seemingly, the molecular nanogels can entrap HYP in the hydrophobic domains of the hydrogel particle, formed by self-assembled molecules of $\mathbf{1}$. In contrast, in the case of RB, most likely adsorption through ion-dipole interactions with the polar units of the gel particle explains its incorporation. The mechanism of cellular uptake of the loaded nanogels is probably endocytosis, considering the precedents in the literature, but has not been studied in this work. Considering that hydrophobic interactions dominate the nanogel selfassembly, it appears feasible that the particles would be disassembled in the cellular medium upon, for example, interaction with proteins.

The results obtained by flow cytometry revealed an effective PDT action for both RB@1 and HYP@1 nanogels, showing no relevant dark toxicity confirming the biocompatibility of the delivery systems. The PDT efficiency compares well with previous reports using different nanocarriers. We believe that the use of nanogels described here presents an added value coming from its molecular nature. Stimuli responsiveness of molecular particles would permit site-specific release/activation of the loaded species. Additionally, the molecular nature of the carrier should favor its biodisposition and avoid reproducibility and polydispersity issues associated with polymeric materials.

Finally, it is worth noting that the versatility of the nanogels could potentially permit simultaneous loading of PS and upconversion nanoparticles, affording IR-promoted PDT, a possibility that may be studied in future work. ${ }^{69}$

\section{METHODS}

Materials and General Methods. Commercially available reagents and high-performance liquid chromatography-grade solvents were used as received and purchased from Sigma-Aldrich and Fisher Scientific unless otherwise stated. PBS tablets were used to prepare a PBS solution containing $0.01 \mathrm{M}$ phosphate buffer, $0.0027 \mathrm{M}$ potassium chloride, and $0.137 \mathrm{M}$ sodium chloride. The $\mathrm{pH}$ was adjusted to 7.0 , and the solution was filtered using a $0.22 \mu \mathrm{m}$ pore nylon filter. Toluene was also filtered through a $0.45 \mu \mathrm{m}$ pore nylon filter. Milli-Q water was always used. RB was used in the sodium dianionic form. HYP was obtained from HWL Analytic GmbH. The solutions containing the PSs were protected from light to avoid photobleaching.

Sonication was carried out with Elmasonic S $60 \mathrm{H}$ (Elma) or Fisherbrand FB15053 (Fisher Scientific) ultrasonic units. Centrifugation was performed in vials using a Hettich EBA 20 centrifuge at room temperature or in Eppendorf tubes $(1.5 \mathrm{~mL})$ using a Beckman Coulter Allegra X-22R centrifuge at $15{ }^{\circ} \mathrm{C}$.

$\mathrm{UV}$-vis absorption spectra of the samples were recorded using a JASCO V-630 spectrophotometer with an ETCS-761 Peltier unit for temperature control. Measurements were performed at $25{ }^{\circ} \mathrm{C}$, and samples were loaded into 1.5 or $3 \mathrm{~mL}$ quartz Suprasil cuvettes, with a $10 \mathrm{~mm}$ optical path length, from Hellma Analytics.

Fluorescence emission spectra were recorded using a JASCO FP8300 spectrofluorometer equipped with an ETC-815 Peltier accessory. Measurements were performed at $25{ }^{\circ} \mathrm{C}$, and samples were loaded into $3 \mathrm{~mL}$ optical glass cuvettes, with a $10 \mathrm{~mm}$ optical path length, from Hellma Analytics.

Size measurements of nanogels were performed by DLS using a Zetasizer Nano ZS (Malvern). Analyses were carried out using a $\mathrm{He}-$ $\mathrm{Ne}$ laser $(633 \mathrm{~nm})$ at a fixed scattering angle of $173^{\circ}$. Automatic optimization of beam focusing and attenuation was applied for each sample. Nanogel suspensions were measured in $3 \mathrm{~mL}$ disposable poly(methyl methacrylate) cuvettes (10 mm optical path length). The particle size was reported as the average of three measurements. Zpotential measurements were performed at $25{ }^{\circ} \mathrm{C}$ using laser Doppler micro-electrophoresis with a Zetasizer Nano ZS (Malvern). $1 \mathrm{~mL}$ of the nanogel suspension was measured in disposable folded capillary $\zeta$ cells (Malvern, DTS1070). The Z-potential is reported as the average of six measures per sample.

Synthesis of (S)-4-((3-Methyl-1-(nonylamino)-1-oxobutan2-yl)amino)-4-oxobutanoic Acid (1) and Nanogel Preparation. The preparation of $\mathbf{1}$ and a detailed study of nanogel formation have been reported previously. ${ }^{9}$

RB@1 Preparation. In a typical example, $7.3 \mu \mathrm{mol}$ of compound 1 and $1 \mathrm{~mL}$ of a $40 \mu \mathrm{M} \mathrm{RB}$ suspension in toluene (well dispersed by sonication and prepared from a $500 \mu \mathrm{M}$ stock of $\mathrm{RB}$ ) were introduced in a screw-capped vial $(4 \mathrm{~mL}$, diameter $=1.3 \mathrm{~cm})$. A pink toluene gel with $\mathrm{RB}$ homogeneously dispersed was obtained after heating (heat gun, $250{ }^{\circ} \mathrm{C}$ ) until complete solution and cooling down to room temperature in a water bath. The solvent from the gel was evaporated in a vacuum oven at $75{ }^{\circ} \mathrm{C}$ for $1 \mathrm{~h}$. Then, the xerogel was hydrated in $2 \mathrm{~mL}$ of PBS for $10 \mathrm{~min}$. The suspension was ultrasonicated for 10 $\mathrm{min}$, and large particles were removed by centrifugation at $6000 \mathrm{rpm}$ for 60 min to yield the RB@1 sample as the supernatant. The amount of $\mathrm{RB}$ in the sample was quantified by measuring the absorbance of $\mathrm{RB}$ and comparing the intensity at the $\lambda_{\max }$ with a calibration curve at $549 \mathrm{~nm}$ of $\mathrm{RB}$ solutions in PBS constructed for the range of concentrations of interest. The procedure could be scaled up to prepare samples of RB@1 of $7 \mathrm{~mL}$ with a similar concentration of RB@1. For control experiments, RB solutions in PBS were used in the same range of concentrations as that calculated for RB in the RB@1 samples.

HYP@1 Preparation. In a typical example, $7.3 \mu \mathrm{mol}$ of compound 1 and $1 \mathrm{~mL}$ of $50 \mu \mathrm{M}$ HYP suspension in toluene (well dispersed by sonication) were introduced in a screw-capped vial $(4 \mathrm{~mL}$, diameter $=$ $1.3 \mathrm{~cm}$ ). Then, the same protocol used for the preparation of RB@1 was followed. The amount of HYP in the samples was quantified by measuring the absorbance of HYP and comparing the intensity at the 
$\lambda_{\max }$ with a calibration curve at $599 \mathrm{~nm}$ of HYP solutions in DMSO built for the range of concentrations of interest. The procedure could be scaled up to prepare samples of HYP@1 of $7 \mathrm{~mL}$ with a similar concentration of HYP@1. For control experiments, HYP solutions at the same concentration as in HYP@1 samples were prepared in PBS containing $1 \% \mathrm{v} / \mathrm{v}$ DMSO (HYP in PBS-DMSO). HYP in PBS controls were prepared following the HYP@1 protocol without 1.

Measurement of ${ }^{1} \mathrm{O}_{2}$ Photogeneration. Samples with a total volume of $2 \mathrm{~mL}$ were placed in a $10 \times 10 \mathrm{~mm}$ fluorescence quartz cuvette containing ABDA $1 \mu \mathrm{M}$ as a ${ }^{1} \mathrm{O}_{2}$ probe (from a $0.625 \mathrm{mM}$ solution in methanol). Oxygen was bubbled through the solution, and the cuvette was closed with a stopper and Parafilm. The sample was then irradiated under continuous stirring with visible light using an LED light for the RB study ( $8.6 \mathrm{~W}$, ca. $400-700 \mathrm{~nm}$ emission output; the lamp was placed as close to the cuvette as possible) and two LED lamps for the HYP study (11 W each, ca. 400-700 nm emission output; the lamps were placed perpendicular to each other at $1 \mathrm{~cm}$ from the cuvette). The cuvette was protected from external light during the process. The evolution of the photoreaction was monitored over time by fluorescence spectroscopy $\left(\lambda_{\mathrm{ex}} 380 \mathrm{~nm}\right)$ following the decrease of ABDA emission intensity at $407 \mathrm{~nm}$. The initial points of the kinetic traces were fitted to a pseudo-first-order model $\left(\ln C / C_{0}=\right.$ $-k_{\text {obs }} \times t$, where $C$ is the concentration of $\mathrm{ABDA}$ at a specific time $t$ and $C_{0}$ is the initial concentration of ABDA).

General Considerations of Biological Assays. The human colon adenocarcinoma (HT-29) cell line was obtained from the American Type Culture Collection. Cell culture media were purchased from Gibco (Thermo Fisher Scientific). FBS was obtained from Harlan Sera-Lab. Supplements and other chemicals not listed in this section were obtained from Sigma-Aldrich. Plastics for cell culture were supplied by Thermo Fisher Scientific. Chambered coverslips from IBIDI were used for confocal microscopy.

The HT-29 cell line was maintained in DMEM containing glucose $(4.5 \mathrm{~g} / \mathrm{L})$, glutamine $(2 \mathrm{mM})$, penicillin $(50 \mu \mathrm{g} / \mathrm{mL})$, streptomycin $(50 \mu \mathrm{g} / \mathrm{mL})$, and amphotericin B $(1.25 \mu \mathrm{g} / \mathrm{mL})$, supplemented with $10 \%$ FBS. The phenol red- or FBS-free medium with the same supplements was used when indicated to avoid fluorescence interferences or to promote starving conditions, respectively. Cells were grown at $37{ }^{\circ} \mathrm{C}$ in a $5 \% \mathrm{CO}_{2}$ humid atmosphere and, unless otherwise indicated, were also kept under these conditions during incubation. Sterilized PBS was used to wash or irradiate cells. Samples were tested in HT-29 cells in a 1:3 dilution with the medium according to the results of the viability of the cells (using the Trypan blue staining method) after $24 \mathrm{~h}$ incubation with nanogels of 1 at different dilutions.

Flow cytometry analysis was performed with a BD Accuri C6 flow cytometer. The data were recorded for at least 30,000 events per sample. When fluorescent probes were used, positive and negative populations were set up using an untreated or negative control cell population.

CLSM analysis was performed on an inverted confocal microscope Leica TCS SP8. Images were obtained with an HC PL APO CS2 $63 \times / 1.40$ oil immersion objective. Excitation of samples was performed with a diode laser excitation, and fluorescence was obtained with a $\mathrm{HyD}$ detector, also recording the transmission.

Flow Cytometry Evaluation of the Cellular Uptake of Loaded Nanogels. HT-29 cells in a 6-/12-well plate $(60-70 \%$ confluence) were incubated for $24 \mathrm{~h}$ with the solutions to be tested (two replicas) in a 1:3 dilution with the FBS-free and phenol red-free media. After incubation, cells were harvested from the culture plates, washed three times with PBS, discarding the supernatant each time, and analyzed by flow cytometry. The internalized probe was excited at $488 \mathrm{~nm}$, and the fluorescence emission per cell was measured using a 670LP filter for both RB and HYP. To be able to compare the data obtained between different experiments, the results were normalized as the percentage of fluorescence intensity/cell over the negative control.

Confocal Microscopy Evaluation of the Cellular Uptake of Loaded Nanogels. HT-29 cells in a $\mu$-slide 8-well ibidi plate (60$70 \%$ confluence) were incubated overnight with the solutions to be tested in a 1:3 dilution with the FBS-, phenol red-free medium. After washing four times with PBS, cells were kept in the FBS-, phenol redfree medium and visualized under the confocal microscope (RB: $\lambda_{\mathrm{ex}}=$ $514 \mathrm{~nm}, \mathrm{HYP}: \lambda_{\mathrm{ex}} 561 \mathrm{~nm}$ ). The quantification of the fluorescence intensity of the cells was performed using ImageJ software, and the results are expressed as the average fluorescence intensity/cell.

PDT Assays. HT-29 cells in a 6-/12-well plate (60-70\% confluence) were incubated for $24 \mathrm{~h}$ with the solutions to be tested (two replicas) in a 1:3 dilution with the phenol red-free medium. After incubation, cells were washed three times with PBS and, while kept in PBS, were irradiated for 2 min with two LED lamps (11 W each, ca. $400-700 \mathrm{~nm}$ emission output) placed as close to the lid of the cell plate as possible, resulting in an irradiance value of $750 \mathrm{~W}$ $\mathrm{m}^{-2}$. In non-irradiated controls, the plate was kept covered in aluminum foil under the same conditions. After another $24 \mathrm{~h}$ incubation in the fresh phenol red-free medium, cells were washed with PBS and harvested. Afterward, cells were stained and analyzed by flow cytometry according to the instructions of the corresponding apoptosis detection kit/FITC Annexin V apoptosis detection kit I (BD Pharmingen, 556547) for RB and the YO-PRO-1/PI Vybrant apoptosis assay kit \#4 (V13243 Invitrogen Thermo Fisher) for HYP. Cell populations were classified into viable (FITC Annexin V/YOPRO-1 and PI-negative), apoptotic (FITC Annexin V/YO-PRO-1positive and PI-negative), and non-viable cells (PI-positive). ${ }^{70}$

\section{ASSOCIATED CONTENT}

\section{Supporting Information}

The Supporting Information is available free of charge at https://pubs.acs.org/doi/10.1021/acsabm.1c00139.

Cell viability obtained for non-irradiated control experiments and unloaded nanogel samples; representative examples of the linear fit of ABDA; UV-vis absorption spectra of HYP in DMSO and PBS; and additional images of CLSM (PDF)

\section{AUTHOR INFORMATION}

\section{Corresponding Authors}

Francisco Galindo - Departament de Química Inorgànica $i$ Orgànica, Universitat Jaume I, Castelló de la Plana 12071, Spain; orcid.org/0000-0003-0826-6084;

Email: francisco.galindo@uji.es

Juan F. Miravet - Departament de Química Inorgànica $i$ Orgànica, Universitat Jaume I, Castelló de la Plana 12071, Spain; orcid.org/0000-0003-0946-3784;

Email: miravet@uji.es

\section{Authors}

Ana Torres-Martínez - Departament de Química Inorgànica $i$ Orgànica, Universitat Jaume I, Castelló de la Plana 12071, Spain

Begoña Bedrina - Departament de Química Inorgànica $i$ Orgànica, Universitat Jaume I, Castelló de la Plana 12071, Spain

Eva Falomir - Departament de Química Inorgànica $i$ Orgànica, Universitat Jaume I, Castelló de la Plana 12071, Spain; orcid.org/0000-0003-0329-6313

María J. Marín - School of Chemistry, University of East Anglia, Norwich NR4 7TJ, U.K.

César A. Angulo-Pachón - Departament de Química Inorgànica i Orgànica, Universitat Jaume I, Castelló de la Plana 12071, Spain

Complete contact information is available at: https://pubs.acs.org/10.1021/acsabm.1c00139 


\section{Author Contributions}

The manuscript was written through the contributions of all authors. All authors have given approval to the final version of the manuscript.

\section{Notes}

The authors declare no competing financial interest.

\section{ACKNOWLEDGMENTS}

Ministerio de Economía y Competitividad of Spain (grants CTQ2015-71004-R and RTI2018-101675-B-I00) and Universitat Jaume I (grant UJI-B2018-54) are thanked for financial support. A.T.-M. thanks Ministerio de Educación, Cultura y Deporte of Spain for an FPU fellowship (FPU14/05974). Technical support from SCIC of Universitat Jaume I is acknowledged.

\section{REFERENCES}

(1) Pelaz, B.; Alexiou, C.; Alvarez-Puebla, R. A.; Alves, F.; Andrews, A. M.; Ashraf, S.; Balogh, L. P.; Ballerini, L.; Bestetti, A.; Brendel, C.; Bosi, S.; Carril, M.; Chan, W. C. W.; Chen, C.; Chen, X.; Chen, X.; Cheng, Z.; Cui, D.; Du, J.; Dullin, C.; Escudero, A.; Feliu, N.; Gao, M.; George, M.; Gogotsi, Y.; Grünweller, A.; Gu, Z.; Halas, N. J.; Hampp, N.; Hartmann, R. K.; Hersam, M. C.; Hunziker, P.; Jian, J.; Jiang, X.; Jungebluth, P.; Kadhiresan, P.; Kataoka, K.; Khademhosseini, A.; Kopeček, J.; Kotov, N. A.; Krug, H. F.; Lee, D. S.; Lehr, C.-M.; Leong, K. W.; Liang, X.-J.; Ling Lim, M.; LizMarzán, L. M.; Ma, X.; Macchiarini, P.; Meng, H.; Möhwald, H.; Mulvaney, P.; Nel, A. E.; Nie, S.; Nordlander, P.; Okano, T.; Oliveira, J.; Park, T. H.; Penner, R. M.; Prato, M.; Puntes, V.; Rotello, V. M.; Samarakoon, A.; Schaak, R. E.; Shen, Y.; Sjöqvist, S.; Skirtach, A. G.; Soliman, M. G.; Stevens, M. M.; Sung, H.-W.; Tang, B. Z.; Tietze, R.; Udugama, B. N.; VanEpps, J. S.; Weil, T.; Weiss, P. S.; Willner, I.; Wu, Y.; Yang, L.; Yue, Z.; Zhang, Q.; Zhang, Q.; Zhang, X.-E.; Zhao, Y.; Zhou, X.; Parak, W. J. Diverse Applications of Nanomedicine. ACS Nano 2017, 11, 2313-2381.

(2) Bobo, D.; Robinson, K. J.; Islam, J.; Thurecht, K. J.; Corrie, S. R. Nanoparticle-Based Medicines: A Review of FDA-Approved Materials and Clinical Trials to Date. Pharm. Res. 2016, 33, 2373-2387.

(3) Soni, K. S.; Desale, S. S.; Bronich, T. K. Nanogels: An overview of properties, biomedical applications and obstacles to clinical translation. J. Controlled Release 2016, 240, 109-126.

(4) Vinogradov, S.; Batrakova, E.; Kabanov, A. Poly(ethylene glycol)-polyethyleneimine NanoGel(TM) particles: Novel drug delivery systems for antisense oligonucleotides. Colloids Surf., B 1999, 16, 291-304.

(5) Rösler, A.; Vandermeulen, G. W. M.; Klok, H.-A. Advanced drug delivery devices via self-assembly of amphiphilic block copolymers. Adv. Drug Delivery Rev. 2001, 53, 95-108.

(6) Akiyoshi, K.; Deguchi, S.; Tajima, H.; Nishikawa, T.; Sunamoto, $\mathrm{J}$. Microscopic structure and thermoresponsiveness of a hydrogel nanoparticle by self-assembly of a hydrophobized polysaccharide. Macromolecules 1997, 30, 857-861.

(7) Thelu, H. V. P.; Albert, S. K.; Golla, M.; Krishnan, N.; Ram, D.; Srinivasula, S. M.; Varghese, R. Size controllable DNA nanogels from the self-assembly of DNA nanostructures through multivalent hostguest interactions. Nanoscale 2018, 10, 222-230.

(8) Torres-Martínez, A.; Angulo-Pachón, C. A.; Galindo, F.; Miravet, J. F. Liposome-Enveloped Molecular Nanogels. Langmuir 2019, 35, 13375-13381.

(9) Torres-Martínez, A.; Angulo-Pachón, C. A.; Galindo, F.; Miravet, J. F. In between molecules and self-assembled fibrillar networks: highly stable nanogel particles from a low molecular weight hydrogelator. Soft Matter 2019, 15, 3565-3572.

(10) Vinogradov, S. V. Nanogels in the race for drug delivery. Nanomedicine 2010, 5, 165-168.

(11) Draper, E. R.; Adams, D. J. Low-Molecular-Weight Gels: The State of the Art. Chem 2017, 3, 390-410.
(12) Shi, J.; Kantoff, P. W.; Wooster, R.; Farokhzad, O. C. Cancer nanomedicine: progress, challenges and opportunities. Nat. Rev. Cancer 2017, 17, 20-37.

(13) Donohoe, C.; Senge, M. O.; Arnaut, L. G.; Gomes-da-Silva, L. C. Cell death in photodynamic therapy: From oxidative stress to antitumor immunity. Biochim. Biophys. Acta, Rev. Cancer 2019, 1872, 188308.

(14) Dolmans, D. E. J. G. J.; Fukumura, D.; Jain, R. K. Photodynamic therapy for cancer. Nat. Rev. Cancer 2003, 3, 380.

(15) Foote, C. S. Definition of type I and type II photosensitized oxidation. Photochem. Photobiol. 1991, 54, 659.

(16) Tynga, I. M.; Abrahamse, H. Nano-mediated photodynamic therapy for cancer: Enhancement of cancer specificity and therapeutic effects. Nanomaterials 2018, 8, 923.

(17) Neckers, D. C. Rose Bengal. J. Photochem. Photobiol., A 1989, 47, 1-29.

(18) Fabregat, V.; Burguete, M. I.; Luis, S. V.; Galindo, F. Improving photocatalytic oxygenation mediated by polymer supported photosensitizers using semiconductor quantum dots as "light antennas". RSC Adv. 2017, 7, 35154-35158.

(19) Burguete, M. I.; Galindo, F.; Gavara, R.; Luis, S. V.; Moreno, M.; Thomas, P.; Russell, D. A. Singlet oxygen generation using a porous monolithic polymer supported photosensitizer: Potential application to the photodynamic destruction of melanoma cells. Photochem. Photobiol. Sci. 2009, 8, 37-44.

(20) Croce, A. C.; Wyroba, E.; Bottiroli, G. Distribution and retention of rose bengal and disulphonated aluminium phthalocyanine: A comparative study in unicellular eukaryote. J. Photochem. Photobiol., B 1992, 16, 318-330.

(21) Sztandera, K.; Gorzkiewicz, M.; Klajnert-Maculewicz, B. Nanocarriers in photodynamic therapy-in vitro and in vivo studies. Wiley Interdiscip. Rev.: Nanomed. Nanobiotechnol. 2020, 12, No. e1509.

(22) Uppal, A.; Jain, B.; Gupta, P. K.; Das, K. Photodynamic Action of Rose Bengal Silica Nanoparticle Complex on Breast and Oral Cancer Cell Lines. Photochem. Photobiol. 2011, 87, 1146-1151.

(23) Dabrzalska, M.; Janaszewska, A.; Zablocka, M.; Mignani, S.; Majoral, J. P.; Klajnert-Maculewicz, B. Cationic Phosphorus Dendrimer Enhances Photodynamic Activity of Rose Bengal against Basal Cell Carcinoma Cell Lines. Mol. Pharm. 2017, 14, 1821-1830.

(24) Wang, B.; Wang, J.-H.; Liu, Q.; Huang, H.; Chen, M.; Li, K.; Li, C.; Yu, X.-F.; Chu, P. K. Rose-bengal-conjugated gold nanorods for invivo photodynamic and photothermal oral cancer therapies. Biomaterials 2014, 35, 1954-1966.

(25) Gianotti, E.; Martins Estevão, B.; Cucinotta, F.; Hioka, N.; Rizzi, M.; Renò, F.; Marchese, L. An Efficient Rose Bengal Based Nanoplatform for Photodynamic Therapy. Chem.-Eur. J. 2014, 20, 10921-10925.

(26) Wang, X.-L.; Zeng, Y.; Zheng, Y.-Z.; Chen, J.-F.; Tao, X.; Wang, L.-X.; Teng, Y. Rose bengal-grafted biodegradable microcapsules: Singlet-oxygen generation and cancer-cell incapacitation. Chem.-Eur. J. 2011, 17, 11223-11229.

(27) Chaudhuri, S.; Sardar, S.; Bagchi, D.; Dutta, S.; Debnath, S.; Saha, P.; Lemmens, P.; Pal, S. K. Photoinduced Dynamics and Toxicity of a Cancer Drug in Proximity of Inorganic Nanoparticles under Visible Light. ChemPhysChem 2016, 17, 270-277.

(28) Sabri, T.; Pawelek, P. D.; Capobianco, J. A. Dual Activity of Rose Bengal Functionalized to Albumin-Coated Lanthanide-Doped Upconverting Nanoparticles: Targeting and Photodynamic Therapy. ACS Appl. Mater. Interfaces 2018, 10, 26947-26953.

(29) Karthikeyan, K.; Babu, A.; Kim, S.-J.; Murugesan, R.; Jeyasubramanian, K. Enhanced photodynamic efficacy and efficient delivery of Rose Bengal using nanostructured poly(amidoamine) dendrimers: Potential application in photodynamic therapy of cancer. Cancer Nanotechnol. 2011, 2, 95-103.

(30) Jendželovská, Z.; Jendželovský, R.; Kuchárová, B.; Fedoročko, P. Hypericin in the Light and in the Dark: Two Sides of the Same Coin. Front. Plant Sci. 2016, 7, 560.

(31) López-Chicón, P.; Paz-Cristobal, M. P.; Rezusta, A.; Aspiroz, C.; Royo-Cañas, M.; Andres-Ciriano, E.; Gilaberte, Y.; Agut, M.; 
Nonell, S. On the mechanism of Candida spp. photoinactivation by hypericin. Photochem. Photobiol. Sci. 2012, 11, 1099-1107.

(32) Agostinis, P.; Vantieghem, A.; Merlevede, W.; De Witte, P. A. M. Hypericin in cancer treatment: More light on the way. Int. J. Biochem. Cell Biol. 2002, 34, 221-241.

(33) Vandenbogaerde, A. L.; Cuveele, J. F.; Proot, P.; Himpens, B. E.; Merlevede, W. J.; De Witte, P. A. Differential cytotoxic effects induced after photosensitization by hypericin. J. Photochem. Photobiol., B 1997, 38, 136-142.

(34) Noell, S.; Mayer, D.; Strauss, W. S. L.; Tatagiba, M. S.; Ritz, R. Selective enrichment of hypericin in malignant glioma: Pioneering in vivo results. Int. J. Oncol. 2011, 38, 1343-1348.

(35) Rook, A. H.; Wood, G. S.; Duvic, M.; Vonderheid, E. C.; Tobia, A.; Cabana, B. A phase II placebo-controlled study of photodynamic therapy with topical hypericin and visible light irradiation in the treatment of cutaneous T-cell lymphoma and psoriasis. J. Am. Acad. Dermatol. 2010, 63, 984-990.

(36) Rezusta, A.; López-Chicón, P.; Paz-Cristobal, M. P.; AlemanyRibes, M.; Royo-Díez, D.; Agut, M.; Semino, C.; Nonell, S.; Revillo, M. J.; Aspiroz, C.; Gilaberte, Y. In vitro fungicidal photodynamic effect of hypericin on candida species. Photochem. Photobiol. 2012, 88, 613-619.

(37) Saw, C. L. L.; Olivo, M.; Soo, K. C.; Heng, P. W. S. Delivery of hypericin for photodynamic applications. Cancer Lett. 2006, 241, 2330.

(38) Lajos, G.; Jancura, D.; Miskovsky, P.; García-Ramos, J. V.; Sanchez-Cortes, S. Surface-enhanced fluorescence and raman scattering study of antitumoral drug hypericin: An effect of aggregation and self-spacing depending on pH. J. Phys. Chem. C 2008, 112, 12974-12980.

(39) Mondon, K.; Zeisser-Labouèbe, M.; Gurny, R.; Möller, M. MPEG-hexPLA micelles as novel carriers for hypericin, a fluorescent marker for use in cancer diagnostics. Photochem. Photobiol. 2011, 87, 399-407.

(40) Lima, A. M.; Pizzol, C. D.; Monteiro, F. B. F.; Creczynski-Pasa, T. B.; Andrade, G. P.; Ribeiro, A. O.; Perussi, J. R. Hypericin encapsulated in solid lipid nanoparticles: Phototoxicity and photodynamic efficiency. J. Photochem. Photobiol., B 2013, 125, 146-154.

(41) Nafee, N.; Youssef, A.; El-Gowelli, H.; Asem, H.; Kandil, S. Antibiotic-free nanotherapeutics: Hypericin nanoparticles thereof for improved in vitro and in vivo antimicrobial photodynamic therapy and wound healing. Int. J. Pharm. 2013, 454, 249-258.

(42) Lopera, A. A.; Montoya, A.; Vélez, I. D.; Robledo, S. M.; Garcia, C. P. Synthesis of calcium phosphate nanostructures by combustion in solution as a potential encapsulant system of drugs with photodynamic properties for the treatment of cutaneous leishmaniasis. Photodiagn. Photodyn. Ther. 2018, 21, 138-146.

(43) Shao, C.; Shang, K.; Xu, H.; Zhang, Y.; Pei, Z.; Pei, Y. Facile fabrication of hypericin-entrapped glyconanoparticles for targeted photodynamic therapy. Int. J. Nanomed. 2018, 13, 4319-4331.

(44) Josefsen, L. B.; Boyle, R. W. Photodynamic therapy: novel third-generation photosensitizers one step closer? Br. J. Pharmacol. 2008, 154, 1-3.

(45) Konan, Y. N.; Gurny, R.; Allémann, E. State of the art in the delivery of photosensitizers for photodynamic therapy. J. Photochem. Photobiol., B 2002, 66, 89-106.

(46) Arnau-del-Valle, C.; Felip-León, C.; Angulo-Pachón, C. A.; Galindo, F.; Miravet, J. F. Adsorption of Rose Bengal on a selfassembled fibrillar network affords a thermally switchable oxygenation photocatalyst and a thermochromic soft material. J. Photochem. Photobiol., A 2020, 387, 112142.

(47) Bhowmik, B. B.; Ganguly, P. Photophysics of xanthene dyes in surfactant solution. Spectrochim. Acta, Part A 2005, 61, 1997-2003.

(48) Ross, M. I. Intralesional therapy with PV-10 (Rose Bengal) for in-transit melanoma. J. Surg. Oncol. 2014, 109, 314-319.

(49) Kochevar, I. E.; Bouvier, J.; Lynch, M.; Chi-Wei, L. Influence of dye and protein location on photosensitization of the plasma membrane. Biochim. Biophys. Acta 1994, 1196, 172-180.
(50) Valenzeno, D. P.; Trudgen, J.; Hutzenbuhler, A.; Milne, M. Singlet oxygen involvement in photohemolysis sensitized by merocyanine-540 and rose bengal. Photochem. Photobiol. 1987, 46, 985-990.

(51) Wieder, M. E.; Hone, D. C.; Cook, M. J.; Handsley, M. M.; Gavrilovic, J.; Russell, D. A. Intracellular photodynamic therapy with photosensitizer-nanoparticle conjugates: Cancer therapy using a 'Trojan horse'. Photochem. Photobiol. Sci. 2006, 5, 727-734.

(52) Sahay, G.; Alakhova, D. Y.; Kabanov, A. V. Endocytosis of nanomedicines. J. Controlled Release 2010, 145, 182-195.

(53) Abrams, J.; Telford, W. G.; Rollins, L. The many roads to cell death: Discriminating between apoptosis, necrosis and autophagy. Drug Discovery 2014, 15, 41-46.

(54) Nikoletopoulou, V.; Markaki, M.; Palikaras, K.; Tavernarakis, N. Crosstalk between apoptosis, necrosis and autophagy. Biochim. Biophys. Acta, Mol. Cell Res. 2013, 1833, 3448-3459.

(55) Kessel, D. Apoptosis, Paraptosis and Autophagy: Death and Survival Pathways Associated with Photodynamic Therapy. Photochem. Photobiol. 2019, 95, 119-125.

(56) Panzarini, E.; Inguscio, V.; Dini, L. Timing the multiple cell death pathways initiated by Rose Bengal acetate photodynamic therapy. Cell Death Dis. 2011, 2, No. e169.

(57) Felip-León, C.; Puche, M.; Miravet, J. F.; Galindo, F.; Feliz, M. A spectroscopic study to assess the photogeneration of singlet oxygen by graphene oxide. Mater. Lett. 2019, 251, 45-51.

(58) Hackbarth, S.; Röder, B. Singlet oxygen luminescence kinetics in a heterogeneous environment-identification of the photosensitizer localization in small unilamellar vesicles. Photochem. Photobiol. Sci. 2015, 14, 329-334.

(59) Joniova, J.; Rebič, M.; Strejčková, A.; Huntosova, V.; Staničová, J.; Jancura, D.; Miskovsky, P.; Bánó, G. Formation of Large Hypericin Aggregates in Giant Unilamellar Vesicles-Experiments and Modeling. Biophys. J. 2017, 112, 966-975.

(60) Yamazaki, T.; Ohta, N.; Yamazaki, I.; Song, P. S. Excited-state properties of hypericin: Electronic spectra and fluorescence decay kinetics. J. Phys. Chem. 1993, 97, 7870-7875.

(61) Cheng, W.; Fan, F.; Zhang, Y.; Pei, Z.; Wang, W.; Pei, Y. A facile approach for fabrication of core-shell magnetic molecularly imprinted nanospheres towards hypericin. Polymers 2017, 9, 135.

(62) Barras, A.; Boussekey, L.; Courtade, E.; Boukherroub, R. Hypericin-loaded lipid nanocapsules for photodynamic cancer therapy in vitro. Nanoscale 2013, 5, 10562-10572.

(63) Ali, S. M.; Olivo, M. Bio-distribution and subcellular localization of Hypericin and its role in PDT induced apoptosis in cancer cells. Int. J. Oncol. 2002, 21, 531-540.

(64) Vuong, T. T. K.; Vever-Bizet, C.; Bonneau, S.; Bourg-Heckly, G. Hypericin incorporation and localization in fixed HeLa cells for various conditions of fixation and incubation. Photochem. Photobiol. Sci. 2011, 10, 561-568.

(65) Mikeš, J.; Kleban, J.; Sačková, V.; Horváth, V.; Jamborová, E.; Vaculová, A.; Kozubík, A.; Hofmanová, J.; Fedoročko, P. Necrosis predominates in the cell death of human colon adenocarcinoma HT29 cells treated under variable conditions of photodynamic therapy with hypericin. Photochem. Photobiol. Sci. 2007, 6, 758-766.

(66) Marchal, S.; Fadloun, A.; Maugain, E.; D'Hallewin, M.-A.; Guillemin, F.; Bezdetnaya, L. Necrotic and apoptotic features of cell death in response to Foscan photosensitization of HT29 monolayer and multicell spheroids. Biochem. Pharmacol. 2005, 69, 1167-1176.

(67) Timm, M.; Saaby, L.; Moesby, L.; Hansen, E. W. Considerations regarding use of solvents in in vitro cell based assays. Cytotechnology 2013, 65, 887-894.

(68) Kochevar, I. E.; Lambert, C. R.; Lynch, M. C.; Tedesco, A. C. Comparison of photosensitized plasma membrane damage caused by singlet oxygen and free radicals. Biochim. Biophys. Acta, Biomembr. 1996, 1280, 223-230.

(69) Lucky, S. S.; Soo, K. C.; Zhang, Y. Nanoparticles in photodynamic therapy. Chem. Rev. 2015, 115, 1990-2042.

(70) Glisic-Milosavljevic, S.; Waukau, J.; Jana, S.; Jailwala, P.; Rovensky, J.; Ghosh, S. Comparison of apoptosis and mortality 
measurements in peripheral blood mononuclear cells (PBMCs) using multiple methods. Cell Proliferation 2005, 38, 301-311. 